\title{
ASSESSMENT IN NIGERIAN SCHOOLS: A COUNSELLOR'S VIEWPOINT
}

\author{
IDOWU, I. Adeyemi PhD \\ Professor of counselling \\ Department of Guidance and Counselling, \\ University of Ilorin, Nigeria. \\ Presently \\ Provost \\ Adeyemi College of Education, Ondo, Nigeria \\ e-mail: yemidowu2003@yahoo.com \\ and \\ ESERE, O. Mary PhD \\ Lecturer, \\ Faculty of Education, University of Ilorin, \\ P. M. B. 1515, Ilorin, Nigeria \\ e-mail: maryogechim@yahoo.com
}

Abstract

Assessment is aimed at finding out how much a child has acquired in terms of learning skills but also takes into consideration the personal-social development of the child. In Nigerian schools, assessment, most often than not is concentrated on cognitive achievement to the detriment of affective and psychomotor development of learners. This paper reports the findings of a year long survey examining the implementation of Holistic Assessment Measure (WAM) among secondary school teachers in Ilorin, Nigeria. In WAM, a student is assessed as a total entity using all the psychometric devises such as test and non-test techniques. Data were gathered through interviews and focus group with 500 randomly selected teachers. Results suggested that WAM was perceived as useful by $90 \%$ of the teachers to clarify assessment expectations. However, only $5 \%$ of the respondents admitted to employing WAM in the assessment of their students. 95\% of the respondents do not factor affective and psychomotor measure into the overall performance of their students while $10 \%$ of the respondents claimed ignorance and incompetence in the use of non-test devises. It is recommended, that in-service training be organised for secondary school teachers in Nigeria, to educate them more on the need for WAM in the attainment of the overall educational goals.

Key words: Assessment; holistic; secondary schools, Nigeria. 


\section{Introduction}

One of the functions of a school is the certification of the individual learner under its embrace. To effectively carry out this role, assessment of one kind or the other is a prerequisite. Assessment is a means whereby the teacher obtains information about knowledge gains, behavioural changes and other aspects of the development of learners (Oguneye, 2002). It involves the deliberate effort of the teacher to measure the effect of the instructional process as well as the overall effect of school learning on the behaviour of students. Assessment covers all aspects of school experience both within and outside the classroom. It covers the cognitive as well as the affective and psychomotor aspects of learning. This classificatory system covering all aspects of school learning originated from the work of Bloom et al (1971). Bloom and his associates categorized the cognitive domain into six levels of thinking. These are knowledge, understanding, application, analysis, synthesis and evaluation. The affective domain covers such social and personality characteristics as values, attitudes, interest, adjustment, habits, perception, social relations and beliefs. Psychomotor domain involves skills acquired by learners in manipulation, following specified procedures and body movements. It ranges from simple handwriting to drawing, handling of implements, apparatus, vehicles and equipment, playing of instruments and using keyboards, stage performance and dance, games/sporting skills. These three domains are interrelated and interdependent (Oyesola, 1986).

In Nigerian schools, however, assessment, especially at the secondary level, most often than not is concentrated on cognitive achievement to the detriment of affective and psychomotor development of learners (Ipaye, 1986; Iyewarun, 1986; Okon, 1986). This is not unconnected with the Nigerian society's quest for paper qualification. Thus a child with pass marks in his/her subjects receives a certificate at the end of the course no matter how "bad" his/her manners are or how unskilled he/she may be. In other words, behaviour, attitude, interest, aptitude and other affective and psychomotor traits do not count towards obtaining a certificate. Educational evaluators (Iyewarun, 1986; Okon, 1986; Miller, Frank, Franks \& Getto, 1989; Obe, 1991) have prescribed a departure from this trend to make room for a comprehensive picture of the development of learners in the school system. Herein lays the rationale for this study.

\section{The Concept of Holistic Assessment Measure}

In Nigeria, Educational Administrators are now more conscious than ever before of their role in the nationwide scheme of curriculum 
innovation. Not only have new courses been introduced and new contents injected into existing subjects, a fundamental change in the system of assessment of students' performance has also emerged through the formalisation of holistic assessment as a major component of evaluation process (Oyesola, 1986). The term "Holistic Assessment Measure" (the Authors' Coinage) refers to the combined use of assessment measures in the cognitive, affective and psychomotor domains. This invariably implies that the student's behaviour, attitudes, interests, modes of interaction, skills, style of work and a variety of other non-cognitive factors will contribute to the decision made by the teacher on each student.

In section 1 of the National Policy on Education (revised 2004), which deals with the philosophy and goals of education in Nigeria, paragraph $9(\mathrm{~g})$ states that "educational assessment and evaluation shall be liberalized by their being based in whole or in part on continuous assessment of the progress of the individual" (p.9). This statement is well amplified in subsequent sections of the document dealing with Primary Education (Section 4), Secondary Education (Section 5), Tertiary Education and finally in Section 12 which deals with the Planning, Administration and Supervision of Education.

The repeated emphasis being placed on continuous assessment is a clear evidence of its importance. According to Ezewu and Okoye (1986), continuous assessment refers to a systematic and objective process of determining the extent of a student's performance in all the expected changes in his behaviour, from the day he enters upon a course of study and a judicious accumulation of all pieces of information derived from this purpose with a view to using them to guide and shape the student and to serve as basis for making important decisions about the child. In other words, continuous assessment should be objective, systematic, comprehensive, cumulative and guidance oriented. However, the notion of whether continuous assessment is comprehensive or not, places a question mark on the classroom teacher. Does the teacher consider all the various aspects of the child's development (cognitive, affective and psychomotor) in the overall assessment of the student's performance? This is the focus of this study.

Utilising data obtained from Focus Group Discussions and interviews with 500 randomly selected teachers in 10 schools in Ilorin, Nigeria, the study sought to explore assessment strategies in Nigerian secondary schools with a view to finding out (i) the perception of the teachers concerning usefulness of WAM as an assessment strategy and (ii) employment of WAM in assessment of students. This study is 
pertinent and significant especially in the wake of increases in antisocial behaviours and incompetence among most secondary school leavers in Nigeria.

\section{Method \\ Design}

This study employed a qualitative approach to data collection. Qualitative research is particularly appropriate for a study of this nature as it can give depth and details of phenomena that are difficult to convey with quantitative methods (Flick, 2002). Qualitative research is not concerned with representativeness or making inferences about the larger population (Mason, 1996; Strauss \& Corbin, 1999). It seeks to gain rich, comprehensive data from a small number of participants (Maphosa, Shumba, Banda \& Shumba, 2007).

\section{Participants and Setting}

Recruitment of participants for the study was by stratified random selection, guided by the information provided by the Kwara State Teaching Service Commission. Thus the participants for the study comprised 500 teachers (age range 30-55 years; male=198; female=302). Teachers were the central unit of analysis in this study because in any teaching and learning process, the teacher is the key factor, responsible for promoting or restraining children's learning (Koutseline, 1997). It had been planned to select 20 teachers per school (10 male teachers and 10 female teachers), but due to unforeseen constraints, only ten teachers per school eventually participated during the 12 month period (January December, 2007) of the data collection exercise.

\section{Procedure for Data Collection}

Prior to the commencement of the programme, permission to conduct the study was sought from principals of the selected secondary schools where the study was carried out. Thereafter, the participants' consent was sought and obtained. They were equally assured of anonymity and confidentiality.

The data collection exercise was mainly through Focus Group Discussions (FGDs). Focus group discussions produce descriptive data about people own written or spoken and observable behaviour. According to Gibbs (1997), focus group is useful for revealing through interaction, the beliefs, attitudes, experiences and feelings of participants in ways which would not be feasible using other qualitative methods. Litosseliti (2003) points out that compared with other qualitative methods where meaning emerges from the participants, focus group have an 
element of flexibility and adaptability. Their open-ended nature allows the opportunity of gaining insight into the world of participants in their own language and promotes self-disclosure in a friendly environment.

Toward this end, 10 focus group discussions (one for each school) were held with the participants. Each discussion lasted for an average of 1 hour and revolved around two major themes:

- Usefulness of WAM as an assessment strategy

- Employment of WAM in assessment of students

Recording of the FGDs sessions was made through note-taking and also by the use of audio-cassettes.

\section{Method of Data Analysis}

Descriptive analysis was used for the demographic characteristics of the participants and to present the participants' responses on issues surrounding WAM as an assessment strategy. The transcription of the recorded audio cassettes, together with the recorded field notes, provided data for the thematic analysis. Transcripts were read and annotated. Multiple readings of the transcripts were undertaken to identify major themes or ideas revealed by the group members as well as critical words, phrases and examples. The experiences of the participants were compared and contrasted, searching for patterns either made explicitly by participants or derived implicitly. Important and frequently expressed ideas or themes were then studied for pattern of connection and grouped into broader categories. The main themes in the data formed a picture that reflected the assessment practices of all the teachers in the study.

\section{Results}

The results of the demographic data showed that majority of the participants $(60.4 \%)$ were females (Table 1$)$. This is not surprising because Nigerian's secondary education sector is dominated by female teachers (Taiwo, 1980). As Table 1 further showed, not all the teachers $(29.6 \%)$ that formed sample for this study were professionally trained. The National Certificate in Education is currently the lowest qualification in Teacher Education in Nigeria. Table 1 also showed that the participants come from different parts of Nigeria with the Yorubas constituting the highest $(61.8 \%)$.

\section{Usefulness of Holistic Assessment Measure}

Most of the participants (90\%) consented to the fact that WAM is most useful as an assessment strategy (Figure 1), while 10\% of the respondents claimed ignorance and incompetence in the use of non-test devises. 
One participant remarked:

I believe that holistic assessment measure is the best assessment strategy for a part can never be compared to a whole.

Another participant added:

To bring out an overall ability of a learner, a situation where he is assessed in the three domains of learning is better than just basing assessment in the cognitive domain alone.

Yet another added:

WAM is useful because education is not just about intellectual ability; it is about acquisition of interpersonal skills, about right character traits, about discipline about aptitude and skills and all these should be factored in the overall performance of students.

\section{Employment of WAM in assessment of students}

95\% of the participants do not factor affective and psychomotor measure into the overall performance of their students while only $5 \%$ of the participants admitted to employing WAM in the assessment of their students (Figure 2). Assessment in the cognitive domain alone was the commonest amongst the participants (Figure 3).

\section{One participant reported:}

Frankly, apart from cognitive assessment, I have never bothered about other aspects of students' performances.

Another participant added:

I have never factored the affective and psychomotor domains into the overall performance of the students because I do not know how to do it.

Yet another added:

I have always tried to assess my students' performance in the three domains of educational objectives. 
Table 1: Socio-demographic Characteristics of the Participants

\begin{tabular}{|l|l|l|}
\hline Characteristics & $\begin{array}{l}\text { Frequency } \\
(\mathbf{N}=\mathbf{5 0 0 )}\end{array}$ & Percentage \\
\hline Gender & 198 & \\
Male & 302 & 39.6 \\
Female & & 60.4 \\
\hline Educational Qualification & 31 & 6.2 \\
NCE $\sqrt{ }$ & 117 & 24.4 \\
B.A.(Ed) $\sqrt{ }$ & 101 & 20.2 \\
B.Sc.(Ed) $\sqrt{ }$ & 58 & 11.6 \\
PGDE $\sqrt{ }$ & 26 & 5.2 \\
M.A.(Ed) $\sqrt{ }$ & 19 & 3.8 \\
M.Sc.(Ed) $\sqrt{ }$ & 72 & 14.4 \\
B.A. $\times$ & 51 & 10.2 \\
B.Sc. $\times$ & 14 & 2.8 \\
M.A. $\times$ & 11 & 2.2 \\
M.Sc. $\times$ & & \\
\hline Ethnic Group & 91 & 18.2 \\
Hausa & 101 & 20.2 \\
Ibo & 308 & 61.6 \\
Yoruba & & \\
\hline
\end{tabular}

$\sqrt{ }=$ with professional (teaching) qualification

$x=$ without professional (teaching) qualification

Usefulness of WAM as an Assessment Strategy

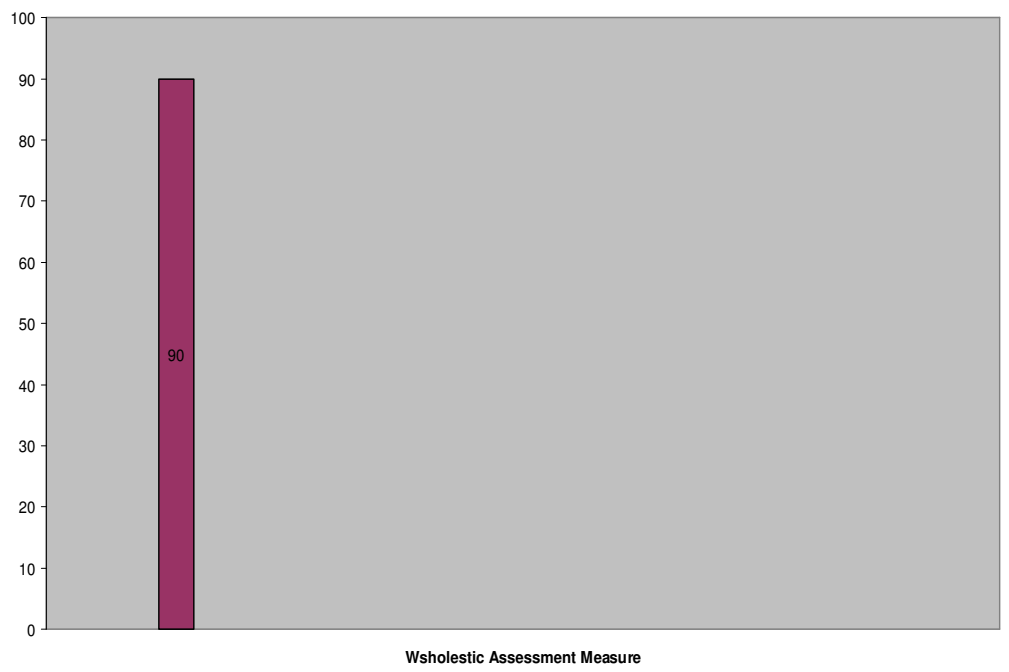

Figure 1: Usefulness of WAM as an Assessment Strategy 
Figure 2: Employment of WAM as an Assessment Strategy

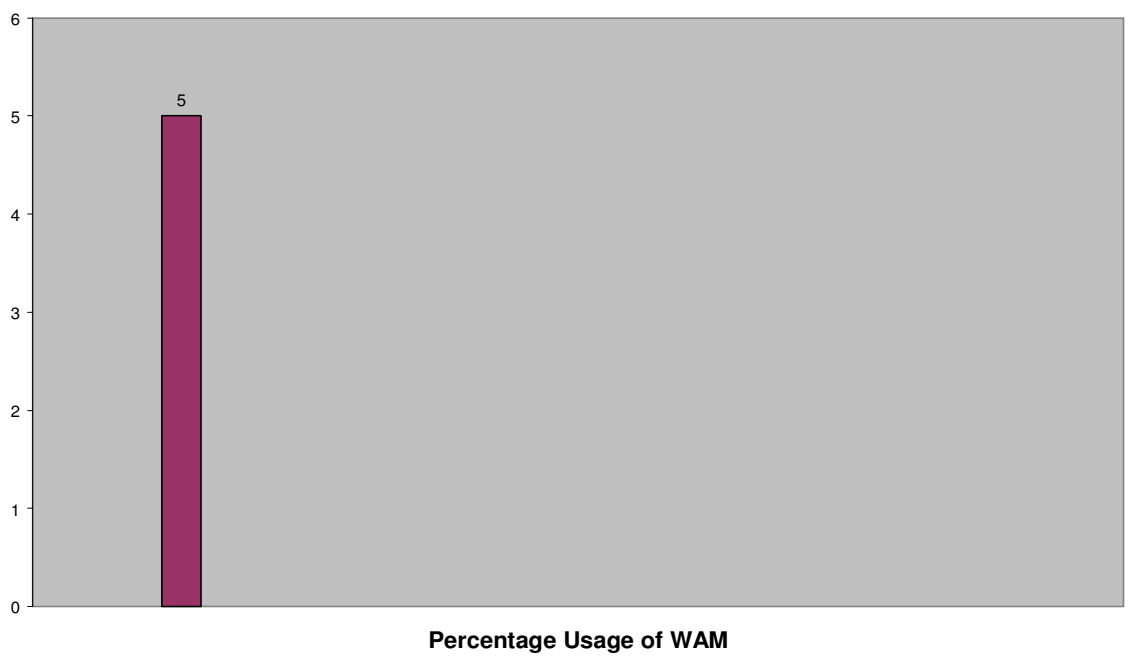

Figure 3: Distribution of Participants by Reported Types of Assessment Measure

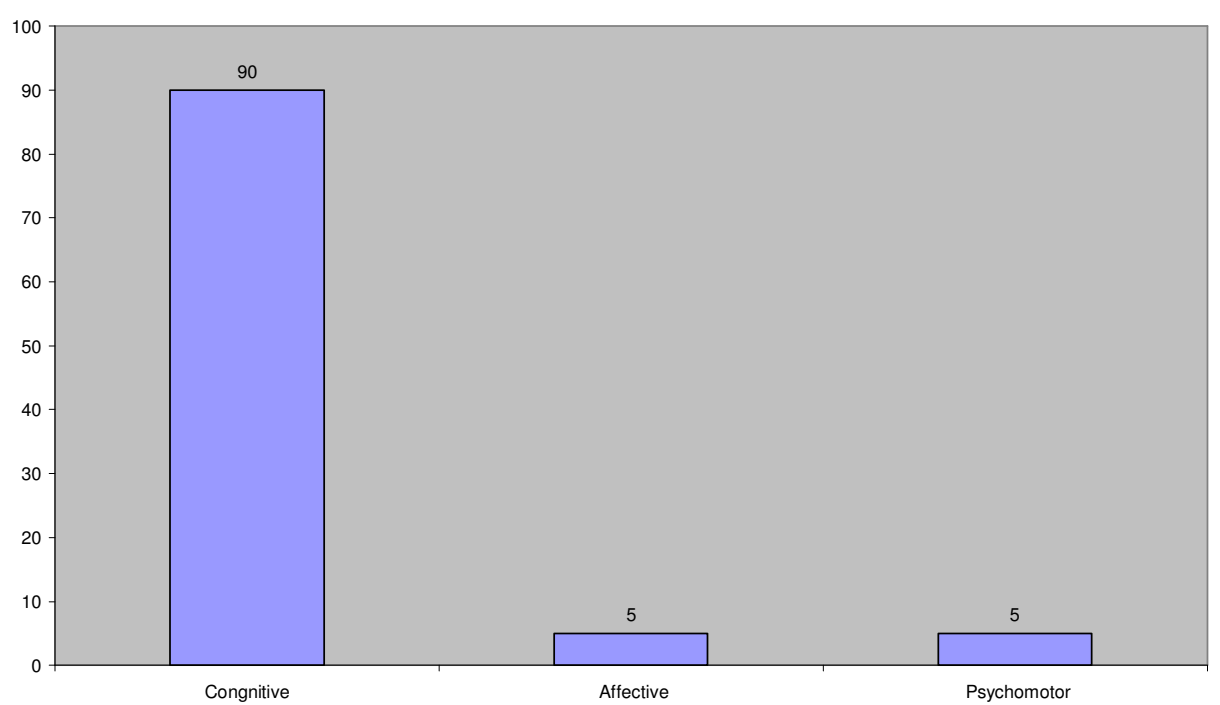

\section{Discussion}

Teaching, learning and assessment are inextricably linked and assessment is the most significant motivator for learning. Results emanating from the current study suggested that WAM was perceived as useful by most of the teachers to clarify assessment expectations and enhance learning thus confirming its alignment to authentic assessment processes. This latest finding lends credence to the work of Olomolaiye (1992) who emphasised 
the value of evaluating the outcomes not only of the cognitive but also the affective and psychomotor development, and the use of such evaluation for the proper guidance of the students. Ndudi (2001) also agrees with Olomolaiye (1992) that in order to assess each learner adequately, and to discover his/her latent skills, knowledge and abilities, teachers should resort to the use of tests with the aim of collecting information with respect to the cognitive, affective and psychomotor domains of learning. It is when a child has been exposed to a variety of learning tasks as well as to conglomerate of assessment devices that valid information could be obtained about the child's overall performance.

The findings emanating from this study as to employment of WAM in the assessment of students showed that assessment in the cognitive domain alone was the commonest among the teachers. This finding runs contrary to educational objectives of Nigeria's national policy on education which emphasises a comprehensive assessment of learners considering all the various aspects of the students' development in the cognitive, affective and psychomotor domains. That most of the teachers are familiar with assessment in the cognitive domain alone (Figure 3) may not be unconnected with the fact that some of them (Table 1) are not professionally trained. This is a worrisome trend in Nigeria's educational system. A situation where people are employed to teach without being trained in the art of teaching should not be. Little wonder some of the teachers are not even aware of what holistic assessment measure is all about and some do not know how to factor affective and psychomotor domains into the overall performance of the students.

\section{Conclusion/Recommendation}

This study investigated assessment in Nigerian schools. Nigeria, in its National Policy on Education has adopted education as an instrument per excellence and for national development. Cognitive-based assessment procedure alone cannot achieve this aim. The trend of thought being followed in this paper therefore is that cognitive knowledge should merge with affective and psychomotor learning. The three of them should be simultaneously assessed and the product used to guide the child's growth. All assessment practices reflect a number of assumptions relating to the nature of learning and the purpose of assessment. If educational institutions intend to equip graduates with attributes necessary for professional practice, for example critical thinking and lifelong learning capabilities, then current assessment practices must be examined.

Toward this end, it is recommended that the government of Nigeria should 
- mandate teachers to go for in-service training and refresher courses to update their knowledge and skills of assessment.

- stop employing people without requisite teaching qualification to teach in Nigerian schools.

\section{References}

Bloom, B. S. et al.(1971). Handbook on formative and summative evaluation of learning. New York: McGraw-Hill Book Company.

Ezewu, E. E \& Okoye, N. N. (1986). Principles and practice of continuous assessment. Ibadan: Evans Publishers.

Federal Republic of Nigeria (2004). National policy on education (4th ed.). Lagos: NERDC Press.

Flick, U. (2002). An introduction to qualitative research. London: Sage.

Gibbs, A. (1997). Focus group social research update, Issue 19, Department of Sociology, University of Surrey.

Iyewarun, S. A. (1986). Traditional methods of examination: Need for a revision. Journal Of Science Teachers Association of Nigeria, 17(3), 146-161.

Ipaye, B. (1986). Continuous assessment in schools with some counselling implications. Ilorin: University of Ilorin Press.

Koutseline, M. (1997). Contemporary trends and perspectives of the curricula: Towards a meta-modern paradigm for curriculum. Curriculum Studies, 5(1), 231-248.

Litosseliti, L. (2003). Using focus groups in research. London: Continuum.

Maphose, C.; Shumba, A.; Banda, W. \& Shumba, J. (2007). The effects of Psychosocial problems on the academic pursuit of AIDS orphans in Zimbabwe. The Nigerian Journal of Guidance and Counselling, 12(1), 1-15.

Miller, G., Frank D., Franks, R. \& Getto, C. (1989). Non-cognitive criteria for assessing students in North American Medical Schools. Acad. Med. 64, 42-45.

Mason, J. (1996). Qualitative researching. London; Sage.

Ndudi, E. (2001). Cognitive and non-cognitive Assessment in Education. Owerri: Century Publishers,

Obe, E. O. (1986). A survey of the attitude of some Lagos secondary school teachers towards continuous assessment. Journal of Research in Curriculum, 1(1), 9-16.

Obe, E. O. (1996). School discipline and remedies. Lagos: Premier Press \& Publishers. 
Oguneye, W. (2002). Continuous assessment: Practice and prospects. Lagos: Providence Publishers.

Okon, S.E.(1986). Guidance for the 6-3-3-4 system of education: A new approach. Ibadan: University Press Ltd.

Olomolaiye, F. (1992). Continuous assessment in Nigerian educational system. A paper presented at the International Curriculum Conference, University of Jos, Jos.

Oyesola, G. O. (1986). Continuous assessment: Some characteristics of a scheme and its organisational implications. Journal of Teacher Education, 2(1), 177-191.

Strauss, A. \& Corbin, J. (1999). Basics of qualitative research. London: Sage.

Taiwo, C. O. (1980). The Nigerian education system: Past, present and future. Lagos: Nelson Publishers Nigeria Ltd. 